\title{
STUDY ON DEFORMATION-INDUCED DAMAGE EVOLUTION FOR INCONEL718 SUPERALLOY WITH THE USE OF AN INNOVATIVE SINGLE-SPECIMEN METHOD
}

\author{
Grzegorz Socha, Bartosz Madejski, Maciej Malicki \\ Institute of Aviation, Warszawa, Poland \\ e-mail: grzegorz.socha@ilot.edu.pl; bartosz.madejski@ilot.edu.pl; maciej.malicki@ilot.edu.pl
}

\begin{abstract}
An innovative method for investigation of deformation-induced damage of elastic-plastic materials is proposed. A static tension test, performed on a specimen with a variable cross-section gage part enabled analysis of degradation of the material structure for all stages of permanent deformation. Modified Johnson model has been used to quantify damage. Analysis of the damage of the specimen surface as well as observations of the damage induced inside the gage part of the specimen has been performed using SEM observations. Debonding at the interface between a hard inclusion and a ductile matrix has been found to be responsible for initiation of cracks on the specimen surface as well as inside the gage part of the specimen. Analysis of the subsequent void growth has been performed. Surface cracks are associated with plastic deformation resulting in an increase of the surface roughness. Variations of the specimen surface roughness have been found to be in good correlation with the damage parameter. This correlation enables the use of surface roughness as the relative damage indicator for the investigated material and deformation mode.
\end{abstract}

Keywords: damage, accumulated plastic strain, superalloy, void growth

\section{Introduction}

Nickel-based superalloys are often used for hot section of aircraft engines. One of the most popular among them is Inconel718. This kind of the material can be characterized by a very good resistivity to mechanical and thermal loads. Usually, hot-section aircraft engine parts are designed to work at high temperature and under high mechanical load, reaching and even exceeding the yield limit. Oversizing parts and decreasing material effort (stress) is usually not possible due to weight reduction requirements. In such service conditions, material damage progresses due to effects related to fatigue, creep and also overload. Monitoring of the damage progress is essential in this case for safety of structures. Monitoring of the progress of material damage preceding formation of detectable cracks is possible only when a proper damage indicator is used. Many damage indicators were used by researchers. A good review of such damage indicators was givenby Yang and Fatemi (1998). The authors divided indicators used to quantify damage into few categories: metallurgical parameters, crack quantification, mechanical parameters and physical measures. Among metallurgical parameters related to plastic deformation that are considered in this paper, one can mention the dislocation number, dislocation cell diameter, slipband density. An attempt to measure dislocation density and its evolution was described by Petersmeier et al. (1998). This kind of investigation is rather difficult to perform due to the fact that determination of any of mentioned parameters requires the use of a sophisticated technique (like TEM) and determination of the average value of such a parameter for a representative volume element (RVE) of the investigated material. Since deformation leads to initiation of microcracks, parameters like the summary (or average) crack length or area are used by researchers, see Yang et al. (2010), Hall (1998), Zhang et al. (1999). For monotonic loading, like static tension reported 
in this paper, microcracks evolve into voids, and the void volume fraction can be used as the damage indicator. This kind of damage indicator was used by Gurson in his well known model (Gurson, 1977). As a matter of fact, any physical quantity can be used as damage indicator if we can only prove that changes of such quantity are related to damage progress. If changes of the damage indicator with progressing damage are monotonic (either increase or decrease during the deformation process), we can quantify damage comparing actual value of such damage indicator with initial one (for virgin material). This kind of the damage indicator can be referred to as relative, and it was used successfully by many researches. One example of the successful use of the relative damage parameter is investigation of fatigue damage accumulation by observation of the local inelastic strain response to constant stress amplitude loading. Results of the investigations were published in series of papers, see Socha (2003, 2004), Socha and Dietrich (2012) together with proposition of the mathematical model for fatigue life estimation.

Another approach to quantify damage of the material is to use cumulative damage indicator. This kind of damage indicator requires integration (or simple summation) of a physical quantity during loading. Such a cumulated value of the damage indicator is then divided by the final value (corresponding to the material failure) to obtain the damage parameter (damage parameter is a normalized value of the damage indicator taking values from 0 for the virgin material to 1 for material failure). A very well known example of such a cumulative damage indicator is, in the case of fatigue loading, the number of applied load cycles. Assuming that for a constant stress amplitude every load cycle introduces the same amount of damage (Palmgren-Miner linear damage rule, see Palmgren (1924), Miner (1945)) into the material, we can define the damage parameter as the ratio of the actual to final (corresponding to failure) number of the elapsed load cycles. A discussion on relative and cumulative damage indicator parameters was given in another author's paper (Socha and Dietrich, 2016).

The most popular material damage model, introduced by Johnson (1980) and then used in almost all FEM codes defines damage as the function of accumulated equivalent plastic strain

$$
D=\sum \frac{\Delta \varepsilon}{\varepsilon_{f}}
$$

where $\Delta \varepsilon$ stands for the accumulated plastic strain and $\varepsilon_{f}$ is the final value of the accumulated plastic strain corresponding to the moment of material failure (original denotation). According to this definition, one can use accumulated equivalent plastic strain as the cumulative damage indicator parameter. This approach was already followed by one of the authors of this paper in the investigation of the fatigue damage accumulation. The results were published in (Socha and Dietrich, 2014). Using the accumulated equivalent plastic strain as the damage indicator parameter has some disadvantages. First of all, the final value of this indicator is related to the stress state, or saying more precisely, is believed to be a function of three invariants of the stress state. This problem is now under intensive investigation by many researchers, see e.g. Bao and Wierzbicki (2004), Nielsen and Hutchinson (2012). Another important question is: what can be considered to be material failure and what is the damage mechanism? In the case of laboratory testing separation of two pieces of a test specimen is usually considered to be the final failure of material, but for the material of the structure in service this approach cannot be applied and the damage of such a material must be observed carefully to detect its failure. Many damage mechanisms were observed by researchers for metallic materials. Most important for elastic-plastic metal alloys are: strain localization (formation of cohesive zone) associated with big plastic deformation in the case of a ductile material, crack initiation and following propagation assisted by plastic deformation around the crack tip or finally brittle fracture in the case ofa brittle material. To investigate the damage mechanism for a particular material and to detect failure (and calculate the corresponding value of $\varepsilon_{f}$ ) observations of structural changes 
undergoing during material deformation are necessary. The aim of this paper is to propose a simple method for investigation of the damage mechanism.

\section{Experimental technique}

Determination of some material properties, like for example elastic constants or yield limit, requires making use of a specimen with a uniform cross-section gage part. Design of the specimen must assure uniform stress and strain distribution in the entire gage part of the specimen. To obtain a credible result of strain measurement, we have to use a technique enabling measurement on big enough volume of a uniformly stressed material (Representative Volume Element). In most cases, such kind of a specimen is used also for damage investigations (Niazi et al., 2013; Ganjiani, 2013; Shen et al., 2014). To investigate the effect of permanent deformation (plastic strain) on the structure of the material, such kind of the specimen is usually deformed to reach a particular level of plastic strain in the entire gage part and then unloaded to perform structural analysis. This kind of technique has some disadvantages. To perform structural analysis on the material of a deformed specimen, it must be destroyed in order to prepare metallographic samples. Due to that fact, it is necessary to perform many tests on many specimens to obtain a complete picture of damage-induced structural changes at various stages of deformation. Such analysis may be influenced by few factors like non-homogeneity of the material structure and properties, different test conditions for specimens and others.

Damage, however, is a local phenomenon. It develops at spots of stress concentration or at imperfections of the structure. Also, as it has already been mentioned, since the material is never perfectly homogeneous, there are always differences in the structure for different specimens, even if they are machined from one piece of the material. For this reason (also due to high cost of many tests), it would be beneficial to perform investigation of damage-induced structural changes on one specimen. Such a kind of the specimen proposed and by authors of this article (Socha et al., 2014), is shown in Fig. 1.

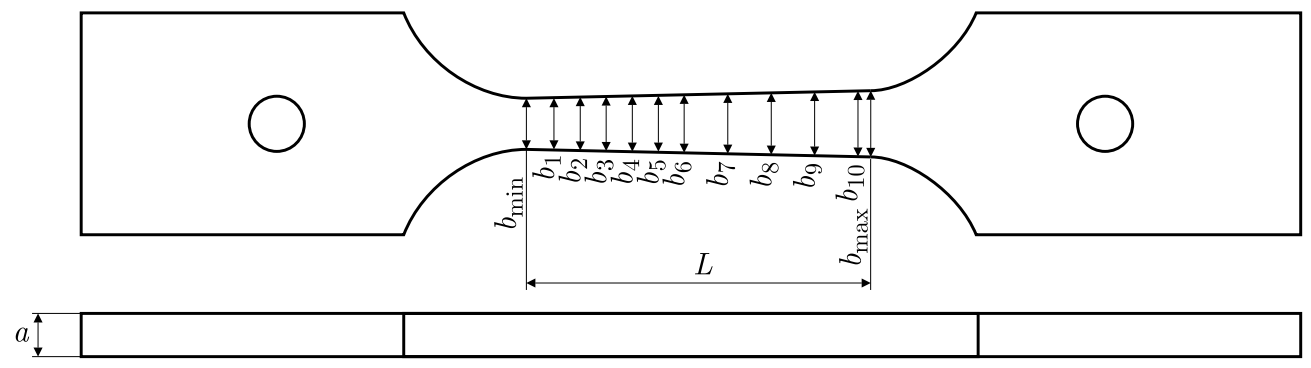

Fig. 1. Specimen for the investigation of deformation induced damage

The gage part of a flat specimen used for this investigations has variable cross-section area. Such a kind of the trapezoidal gage part design enables obtaining continuous distribution of the plastic strain after a tensile test to rupture. Assuming that the length of the gage part of the specimen is $l$, convergence of this trapezoidal gage part is given by formula

$$
1: \frac{\sigma_{Y S} l}{\left(\sigma_{U T S}-\sigma_{Y S}\right) b_{\min }}
$$

where $\sigma_{Y S}$ stands for the yield limit in tension, $\sigma_{U T S}$ stands for the ultimate tensile strength and bmin is the width of the smallest cross-section of the gage part. For a specimen with this convergence of the gage part, after strain localization and necking (formation of cohesive zone) in the narrowest section we shall obtain continuous distribution of plastic strain form the maximum value at that spot to zero at the opposite end of the gage part where the material is expected 
to reach the yield limit at the instant of specimen failure. In this manner, we shall obtain a "frozen" picture of deformation induced damage of the structure for all levels of deformation from purely elastic to permanent deformation corresponding to the final failure of the material. Changes of the structure along the specimen axis reflect progress of damage with an increasing value of the above mentioned damage parameter given by Johnson (1980) that can be modified to a general form for complex stress loading along the non-linear path in the stress space

$$
D=\frac{1}{\bar{\varepsilon}_{f}^{p}} \int d \bar{\varepsilon}^{p}
$$

where the equivalent plastic strain is integrated along the path in the stress space and $\bar{\varepsilon}_{f}^{p}$ stands for its final value at the moment of material failure. In the case of presented investigations, the material is loaded along the linear path in the stress space and original definition (1.1) can be used as well.

The gage part of the specimen is marked along its axis with marks shown in Fig. 1. From the smallest cross-section, six equally distanced marks are put every $3 \mathrm{~mm}$, and then four marks distanced every $5 \mathrm{~mm}$ are added. For these spots of the specimen, the axial plastic strain will be determined based on the incompressibility assumption using the following formula

$$
\varepsilon_{1}=-\left(\varepsilon_{2}+\varepsilon_{3}\right)
$$

where $\varepsilon_{2}$ and $\varepsilon_{3}$ are transversal and in-thickness direction strains. Those strains are calculated on the basis of measurements of the specimen gage part width and thickness before and after the test at selected and marked spots.

Cutting metallographic samples from marked spots along the specimen axis and performing structural observations allows analysis of the damage mechanism and sequence of events during deformation of the material.

\section{Investigated alloy and design of specimens}

The material under investigation is nickel-based Inco 718 alloy (AMS 5596K) in cold rolled and annealed condition. Mechanical properties of the alloy in as received state at room temperature are: $0.2 \%$ offset yield strength $\sigma_{Y S}-445 \mathrm{MPa}$, ultimate tensile strength $\sigma_{U T S}-855 \mathrm{MPa}$, elongation $51 \%$. After heat treatment, the mechanical properties at room temperature are as follows: $\sigma_{Y S}-1150 \mathrm{MPa}, \sigma_{U T S}-1350 \mathrm{MPa}$, elongation $21 \%$. The chemical composition of the alloy is shown in Table 1.

Table 1. Chemical composition of the alloy under investigation [\% weight]

\begin{tabular}{|c|c|c|c|c|c|c|c|}
\hline $\mathrm{C}$ & $\mathrm{Mn}$ & $\mathrm{P}$ & $\mathrm{S}$ & $\mathrm{Si}$ & $\mathrm{Cr}$ & $\mathrm{Ni}$ & $\mathrm{Al}$ \\
\hline \hline 0.05 & 0.01 & 0.008 & 0.0002 & 0.10 & 17.98 & 52.30 & 0.60 \\
\hline $\mathrm{Mo}$ & $\mathrm{Cu}$ & $\mathrm{Cb}$ & $\mathrm{Ta}$ & $\mathrm{Ti}$ & $\mathrm{Co}$ & $\mathrm{B}$ & $\mathrm{Fe}$ \\
\hline \hline 2.88 & 0.02 & 4.97 & 0.01 & 1.02 & 0.04 & 0.02 & 19.96 \\
\hline
\end{tabular}

To verify the above-mentioned strength parameters delivered by a manufacturer, a static tension test has been performed with the use of the standard specimen with the uniform gage part.

Based on the stress-strain curve shown in Fig. 2, mechanical parameters of the alloy are found as follows: $0.2 \%$ offset yield strength $\sigma_{Y S}-450 \mathrm{MPa}$, ultimate tensile strength $\sigma_{U T S}-890 \mathrm{MPa}$, elongation 58\%. Taking into account the results of the static tension test and formula (2.1), the convergence of the shown in Fig. 1 specimen gage part, for the material under investigation has been found to be 1:7.6. 


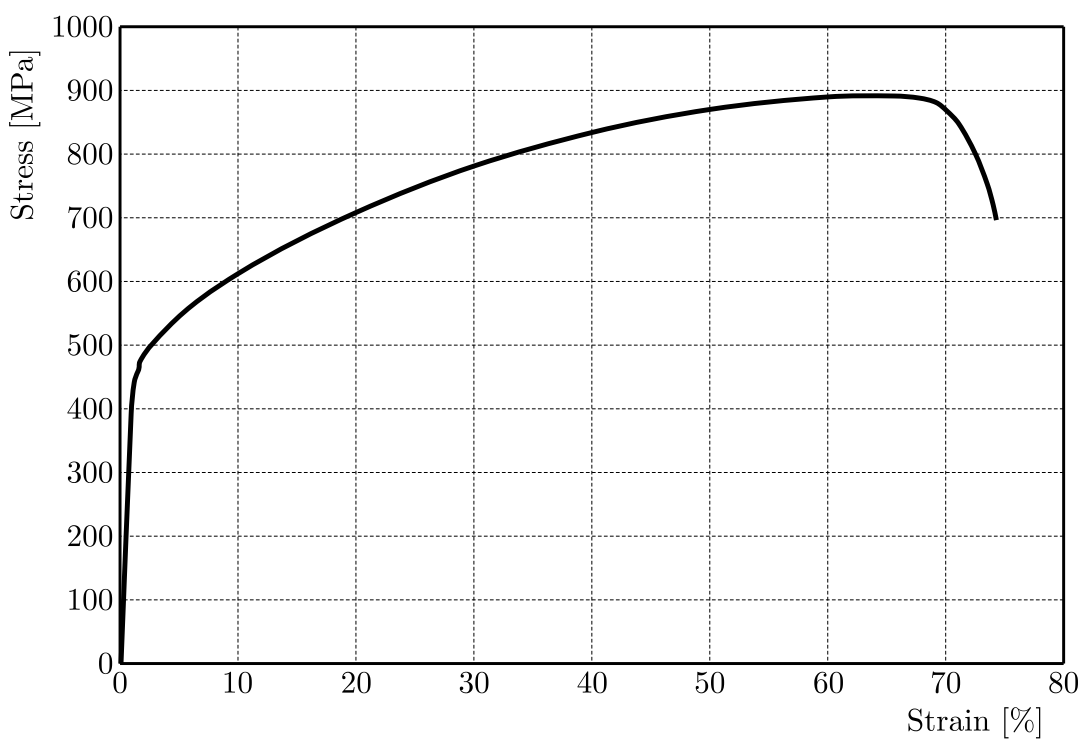

Fig. 2. Stress-strain curve for a static tension test on the standard specimen

\section{Test results}

A static tension test has been performed on a specimen with variable cross-section of the gage part at the room temperature. Both tests were displacement controlled with the rate $0.1 \mathrm{~mm} / \mathrm{min}$ initially and, after elongation of the gage part reached $1.5 \%$, with the rate $1.2 \mathrm{~mm} / \mathrm{min}$ to rupture. A force-elongation diagram for the tests are shown in Fig. 3.

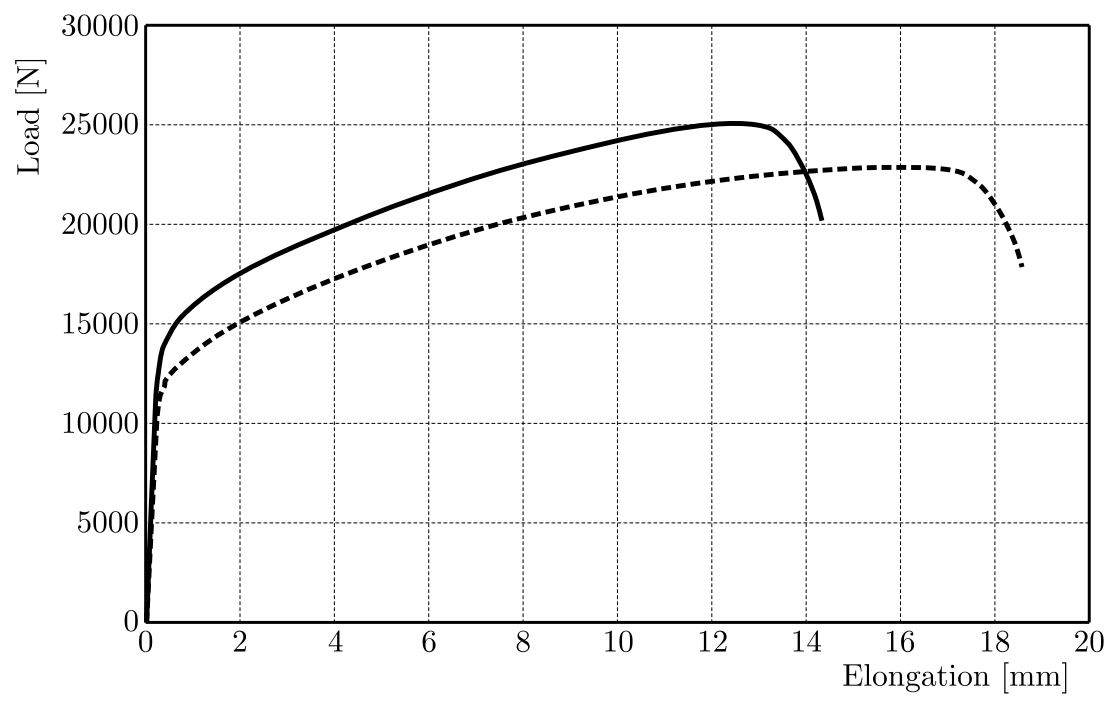

Fig. 3. Force-elongation diagram for the static tension test on a variable gage section specimen

For comparison, a force-elongation diagram for the uniform-gage part specimen (marked with a broken line) is also shown in this figure. As expected, the elongation is bigger for the specimen with the uniform-gage part. This is due to the fact that strain localization (formation of cohesive zone) is delayed for this kind of the specimen comparing to the specimen with a non-uniform cross-section.

As it has been mentioned, the specimen was marked to enable determination of the plastic strain field. The specimen with marks is shown in Fig. 1. Calculations of the axial plastic strain, using formula (2.3), are based on measurements of the specimen at marked points before and 
after the test. Both width and thickness of the specimen have been measured to determine transversal strain in both directions. Distribution of axial strain along the specimen axis is shown in Fig. 4.

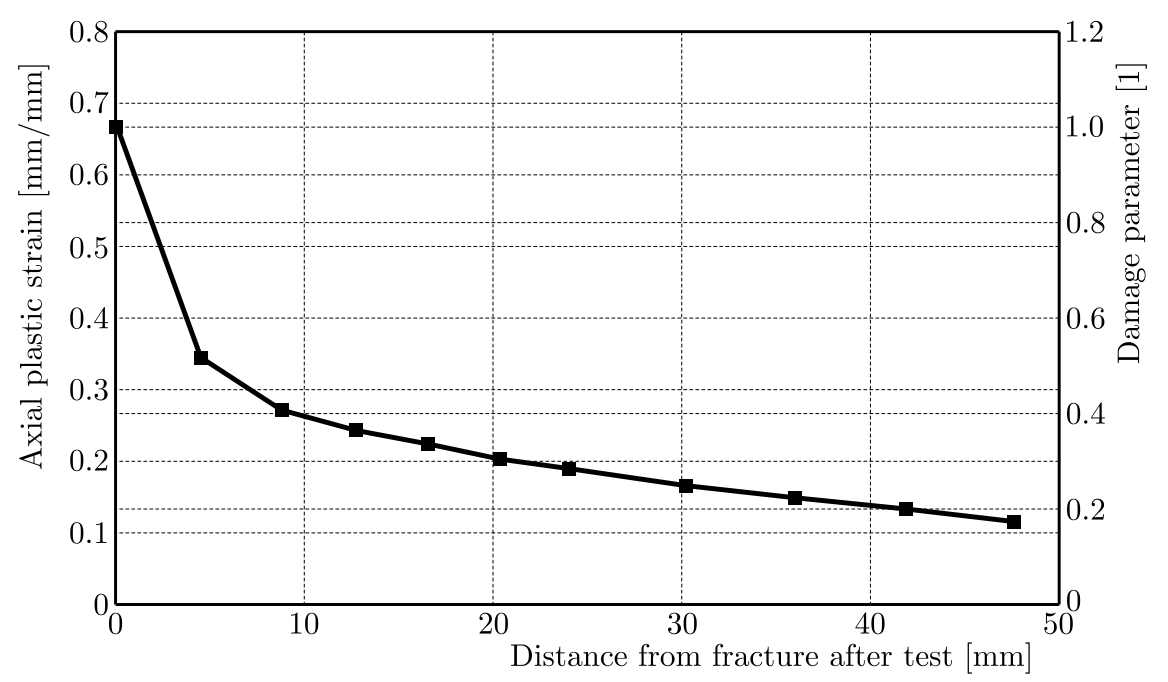

Fig. 4. Distribution of axial plastic strain for a variable gage section specimen

As it can be seen in this figure, the strain is strongly localized in the vicinity of the smallest cross section. Starting from the third mark (about $9 \mathrm{~mm}$ from the smallest cross-section), we can assume that the axial strain changes linearly along the specimen axis. The damage parameter has also been determined on the base of the axial plastic strain calculated for selected sections of the gage part using formula (2.3). The final value of the axial plastic strain $\varepsilon_{f}$ has been calculated for the fracture surface. In Fig. 4, a plot of the damage parameter overlays the plot of the axial strain, but values of the damage parameter are shown on the right axis of the coordinate frame. As it can be seen, the axial plastic strain takes values between 0.1 and 0.68 , while the damage parameter varies from 0.17 to 1 for the fractured surface.

\section{Analysis of the damage mechanism}

For the specimen gage part, outside the cohesive zone, the analysis of deformation-induced damage has been performed using SEM observations of the specimen surface. Figure 5 shows SEM pictures of the specimen surface. The pattern remaining after final surface finishing (grinding) is clearly visible on the specimen surface. Initially straight lines deform with progressing deformation. This deformation illustrates plastic flow of the material around the crack tip. Initially small, finally it forms bands of large plastic deformation between crack tips.

Cracking of the specimen surface occurs at an early stage of deformation $(D=0.19)$ at the interface of hard inclusions and the ductile matrix of the material. The making use of back scattering electron (BSE) technique allowed observation of hard inclusions as light grey areas (this technique is sensitive to chemical composition of the material). The chemical composition of hard inclussions was later investigated with the use of an energy-dispersive X-ray spectroscopy (EDX) technique on a polished material (see Fig. 9) cut off from the specimen gage part. The observations of the deformed surface of the material lead to the conclusion that the main mechanism of material damage in the case of the investigated alloy is the debonding at the interface of the ductile matrix and hard inclusions associated with large plastic deformation around the formed crack tips. 


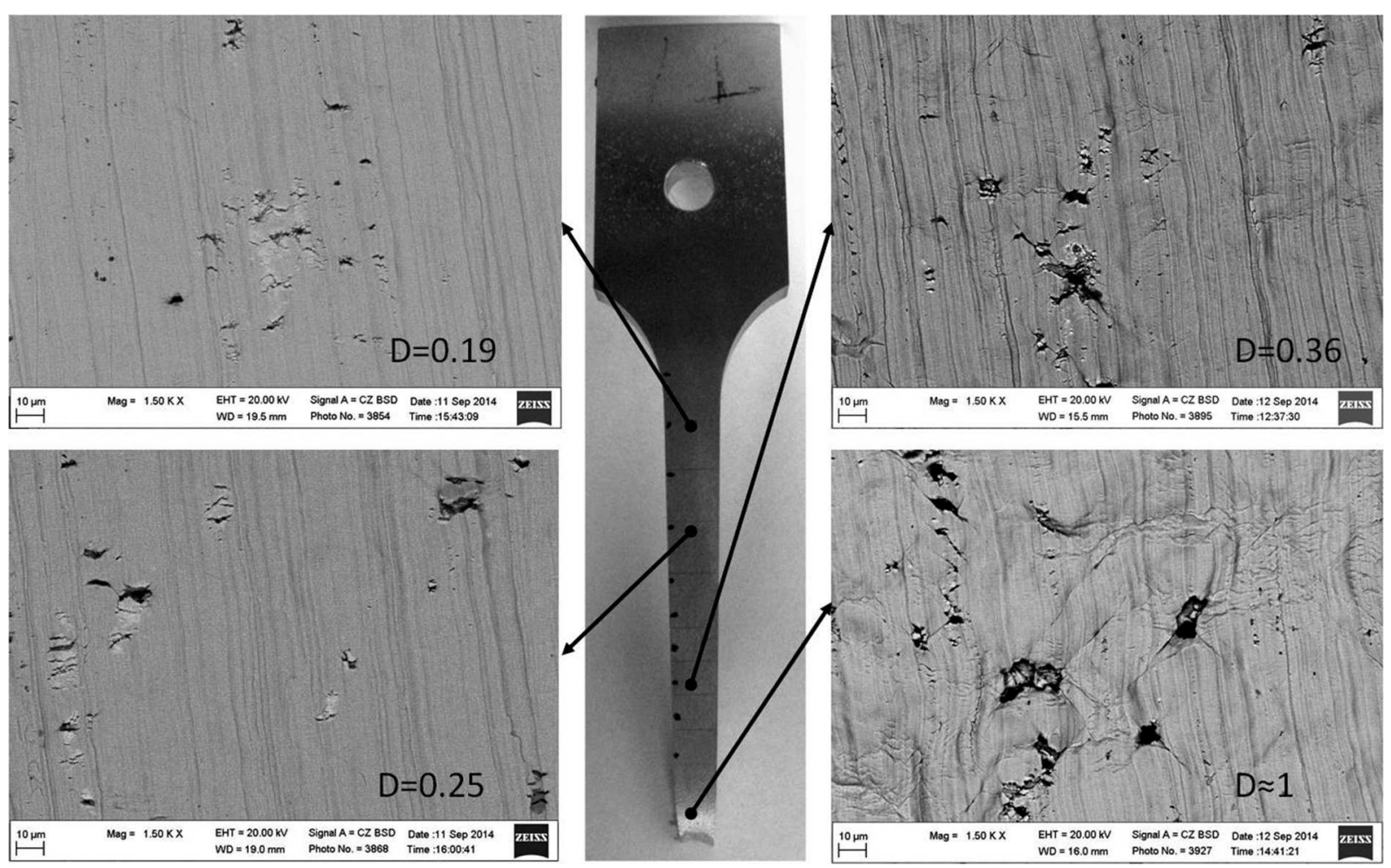

Fig. 5. SEM pictures of the specimen surface
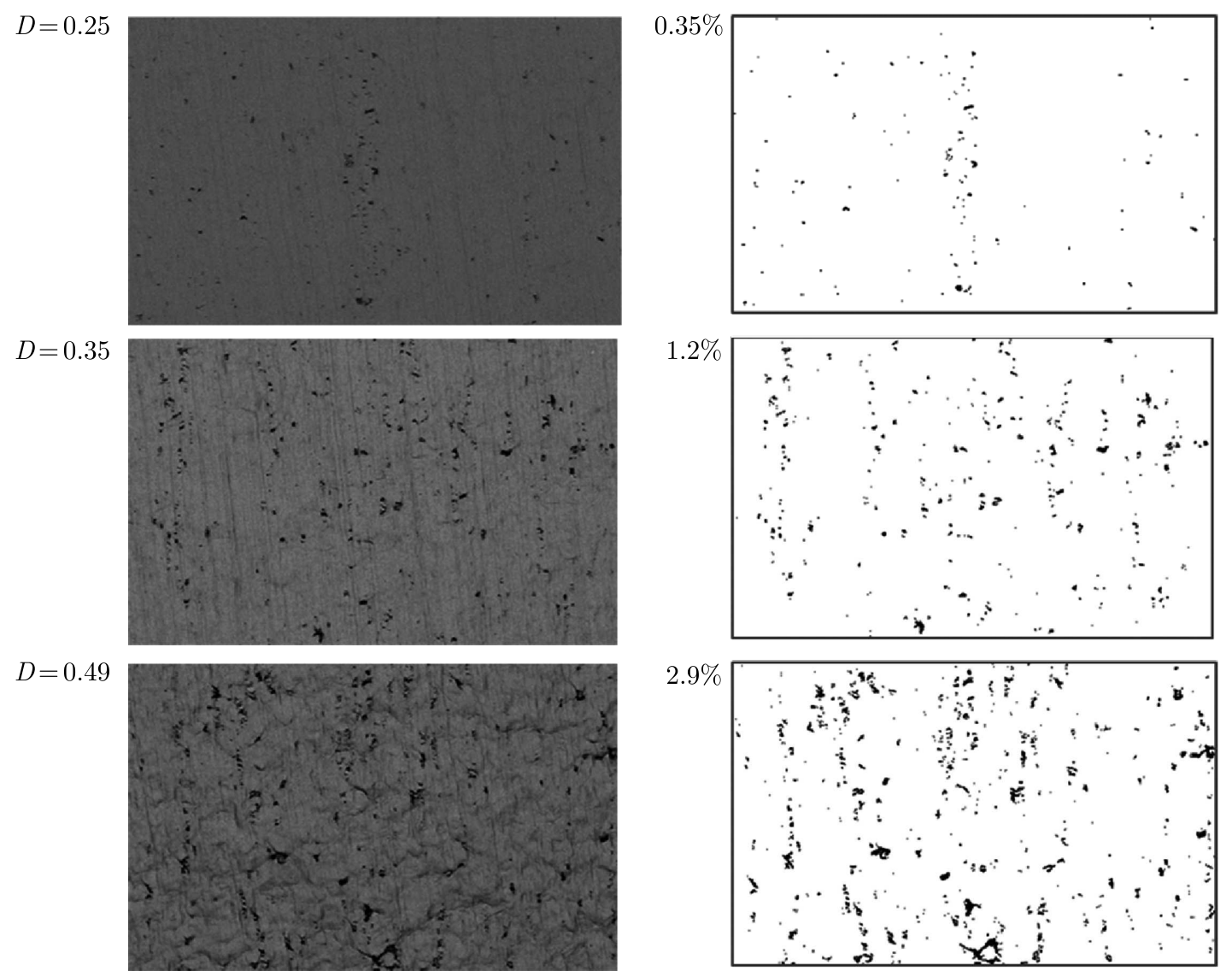

Fig. 6. Development of voids at the surface of the specimen: SEM pictures for the indicated damage degree (left side), corresponding processed pictures with voids patterns and surface void density indicated (right side) 
Under the applied stress field, the debonding of the material at the phase interface develops into voids. Such voids can be seen at the surface of the specimen for consecutive phases of damage accumulation shown in Fig. 6 as dark spots.

SEM pictures taken with the use of BSE technique are shown on the left side of Fig. 6. Back Scattering Electron (BSE) technique allows reproduction of the specimen surface in the grayscale. Lightness gray color corresponds to intensity of the back scattered electron beam making possible the detection of surface cracks and voids as dark spots. This picture is subsequently processed to obtain a black and white pattern of the material discontinuities. The first step of processing is modification of the color curve resulting in an increase in the picture contrast. Lightness and contrast of the picture is then adjusted to obtain a clear pattern of discontinuities. Finally, the picture is binarized (converted into black and white pixels) and the percentage of black pixels is calculated to obtain surface density of cracks (voids) $S$. The surface density of voids is used to calculate the void volume fraction assuming that the voids surface density is the same for three perpendicular planes (which is close to truth near the specimen surface) using the formula

$$
f=S^{\frac{3}{2}}
$$

The void volume fraction $f$ is finally plotted as a function of the damage parameter - see Fig. 7 . The power fit of data points is also shown in this figure together with the equation of the function used. This function can be used to calibrate the well known Gurson model of ductile fracture of elastic-plastic materials (Gurson, 1977).

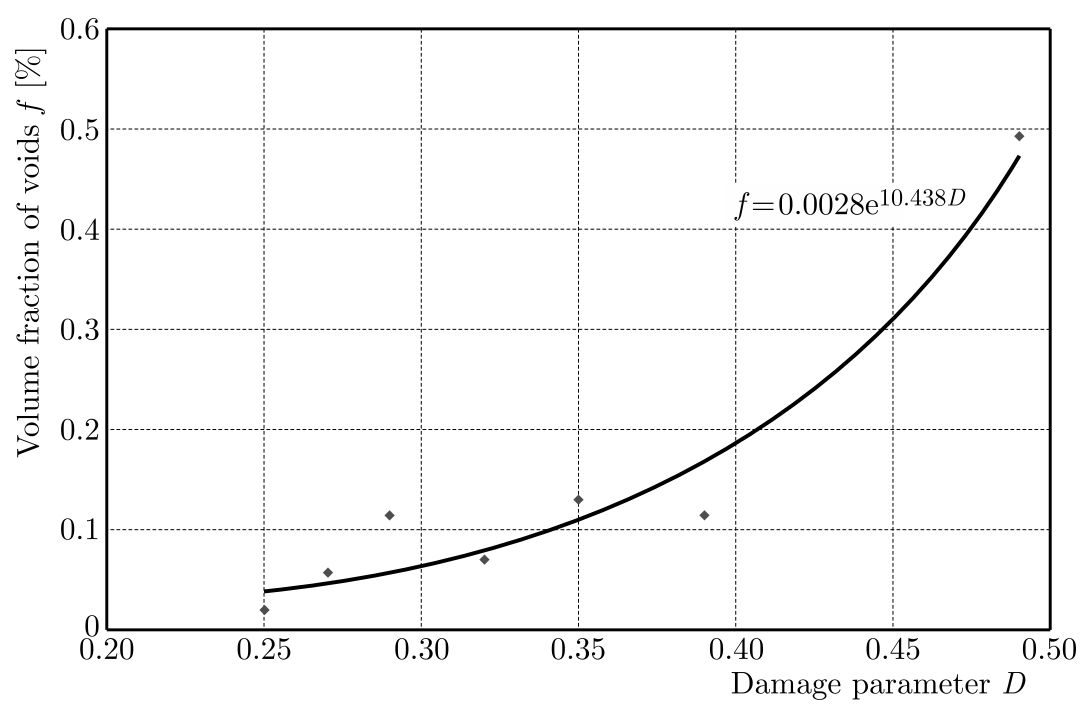

Fig. 7. Void volume fraction $f$ at the surface of the specimen as a function of the damage parameter

The observations of the specimens surface were followed by analysis of the damage induced inside the gage part of the specimen. The specimen was cut along its axis, and metallographic samples were prepared to investigate the internal damage of the material. The samples were taken from locations close to cross sections of the gage part marked in Fig. 1 as the points of plastic strain measurements. SEM pictures of selected metallographic samples are shown in Fig. 8.

The pictures show hard inclusions in the ductile matrix at various stages of the deformation corresponding to the damage parameter indicated in the upper right corner. For a low value of the damage parameter $(D<0.25)$, no damage in form of physical discontinuities of the material exists. The debonding at the phase interface was detected at the deformation corresponding to the damage parameter 0.28 . In Fig. 8, the area of debonding is surrounded by a circle. This 

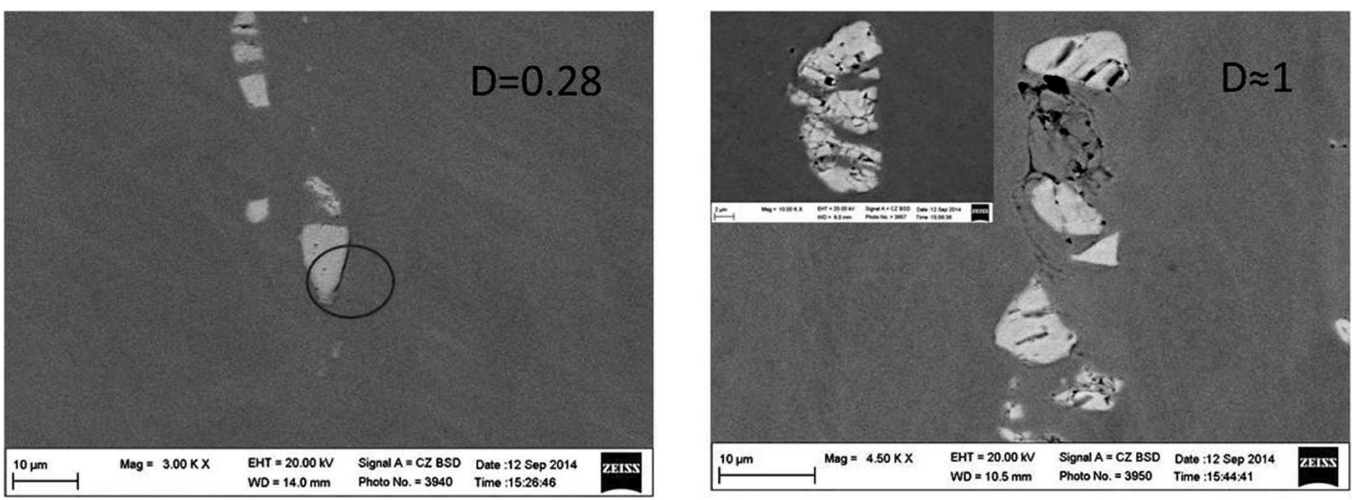

Fig. 8. SEM pictures of the metallographic samples
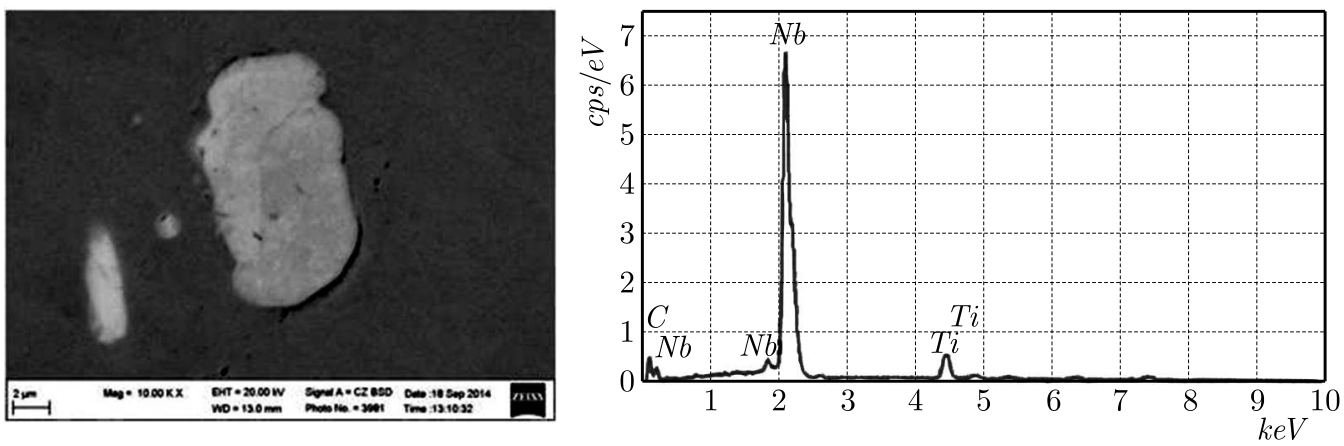

Fig. 9. Debonding of the hard inclusion and its chemical composition

process continues to the stage of advanced deformation, later associated by cracking of hard inclusions and, finally, also cracking of the ductile matrix. In Fig. 9, we can see a SEM picture corresponding to the value of 0.33 of the damage parameter with clearly visible debonding at the phase interface. On the left the chemical composition of hard inclusion can be seen. This hard inclusion can be identified as niobium carbide, and its interface with the ductile matrix seems to be the weakest point of the investigated alloy.

This observation is confirmed in Fig. 10, where the fractured surface of the specimen is shown. The analysis of chemical composition at the bottom of dimple of the fracture surface indicated the same phase, the niobium carbide hard inclusion.
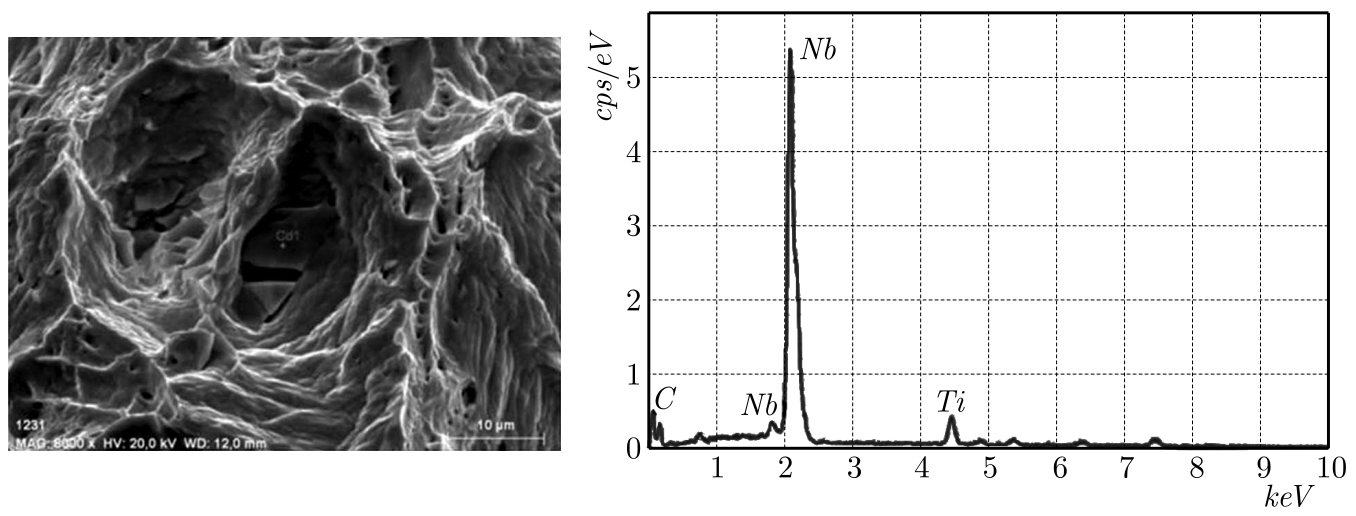

Fig. 10. Fracture surface with niobium carbide at the bottom of dimple

It has to be noticed that, in the case of internal damage analysis, the detection of damage in form of plastic deformation associating cracking on the interface between hard inclusions and the matrix is much more difficult than that on the surface. Also, the debonding can be detected 
later than in the case of the surface of the specimen. Taking this fact into account, we have to notice that the detection of damage is much easier on the specimen surface than inside the material. Since the deformation around surface cracks forms a "orange skin", the magnitude of this deformation should be in some proportion with progressing damage of the material. The easiest way to quantify such kind of deformation is to measure roughness of the specimen surface. The results of measurements are shown in Fig. 11. The correlation of the measured arithmetic average of the absolute values of the amplitude $R_{a}$ and the damage parameter $D$ can be easily seen. The linear fit of the data with the equation is also shown in this figure.

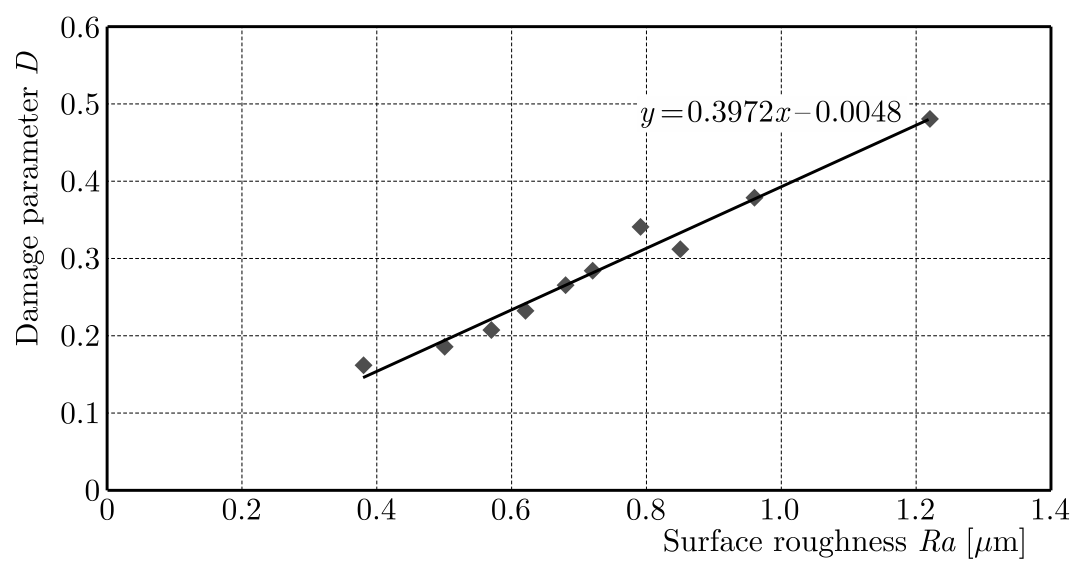

Fig. 11. Correlation between the damage parameter and surface roughness

Assuming that surface roughness increases with the progressing deformation, we can use this parameter as the relative damage indicator. The general formula for damage parameter calculation using the relative damage indicator is as follows

$$
D=\frac{X-X_{0}}{X_{f}-X_{0}}
$$

where $X_{0}, X$ and $X_{f}$ stands for the initial, actual and final value of the damage indicator. To calculate the damage parameter for the deformed material, we have to measure the surface roughness $R_{a}$ and use the following formula derived through linear fit of the data shown in Fig. 11

$$
D=0.4 R_{a}
$$

It has to be stressed that this formula is valid only for the investigated material with a particular surface preparation (initial surface roughness) and for the load scheme applied (static tension). Extending this formula for other cases is not possible. Formula (5.3), however limited to the case of the deformation mode and the material used for presented investigations, is very easy to obtain using results of a simple test. The most important feature of the proposed method is the fact that using such a simple testing technique one can find correlation between damage of the material and plastic deformation, and what follows, one can identify the damage mechanism and critical deformation corresponding to the initiation of material discontinuities.

\section{Conclusions}

A simple experiment performed on the proposed specimen with a variable gage part allows observation of the damage mechanism of a deformed Inconel718 superalloy. Structural changes can be related to progressing deformation of the gage part of the specimen. The changes have 
been observed on the surface of the specimen as well as inside of the gage part. The following conclusions can be drawn:

- The accumulated equivalent plastic strain can be used for quantifying damage of the material subject to simple and complex stress states. Using plastic deformation as the cumulative damage indicator, we can identify the critical value of the damage parameter corresponding to the most important events during deformation (e.g. initiation of material discontinuities). This task is much simplified by using the proposed in this paper investigation technique.

- The debonding of hard inclusions (niobium carbide) at their interface with the ductile matrix has been identified as the main damage mechanism for the investigated Inconel718 superalloy. This phenomenon starts early at the specimen surface, this moment corresponds to the value of the damage parameter $D=0.2$. Inside the material, the debonding starts when the damage parameter reaches approximately 0.3 .

- Cracks at the surface of the specimen are associated with large plastic deformation around their tip. This deformation is clearly visible on SEM pictures showing the specimen surface at various stages of deformation as the pattern of initially straight lines remaining after finishing (grinding).

- Observations of the specimen surface with the use of BSE technique have been used to determine the surface density of material discontinuities. Digital picture processing procedure has been used to calculate the value of this parameter. The surface density of discontinuities (voids) has been then recalculated into the void volume fraction near the specimen surface. The relationship between the void volume fraction and the damage parameter can be used to calibrate the model of material ductile fracture (Gurson, 1977).

- Deformation of the specimen surface allows measurement of the damage parameter using the surface roughness as the relative damage indicator. Derived relationship (5.2) allows estimation of the damage parameter value. This method, however, works only for a particular loading scheme (in the case of presented investigations it has been tension) and for a particular material and surface finishing.

\section{References}

1. BAO Y., WierzBicki T., 2004, On fracture locus in the equivalent strain and stress triaxiality space, International Journal of Mechanical Sciences, 46, 81-89

2. Ganjiani M., 2013, Identification of damage parameters and plastic properties of an anisotropic damage model by micro-hardness measurements, International Journal of Damage Mechanics, 22, $8,1089-1108$

3. Gurson A.L., 1977, Porous rigid-plastic materials containing rigid inclusions - yield function, plastic potential, and void nucleation, Fracture, 2, ICF4, Waterloo, Canada

4. HALl J.A., 1998, Fatigue crack initiation in alpha-beta titanium alloys, International Journal of Fatigue, 19, Supp. 1, S23-S37

5. Johnson G.R., 1980, Materials characterization for computations involving severe dynamic loading, Proceedings of Army Symposium of Solid Mechanics, Cape Cod, Mass., 62-67

6. Miner M.A., 1945, Cumulative damage in fatigue, Journal of Applied Mechanics, 67, A159-A164

7. Niazi M.S., Wisselink H.H., Meinders V.T., van den Boogaard A.H., 2013, Materialinduced anisotropic damage in DP600, International Journal of Damage Mechanics, 22, 7, $1039-1070$ 
8. Nielsen K.L., Hutchinson J.W., 2012, Cohesive traction-separation laws for tearing of ductile metal plates, International Journal of Impact Engineering, 48, 15-23

9. Palmgren A., 1924, Die Lebensdauer von Kugellagern, Verfahrenstechnik, Berlin, 68, 339-341

10. Petersmeier T., Martin U., Eifler D., Oettel H., 1998, Cyclic fatigue loading and characterization of dislocation evolution in the ferritic steel X22CrMoV121, International Journal of Fatigue, 20, 3, 251-255

11. Shen J., Mao J., Boileau J., Chow C.L., 2014, Material damage evaluation with measured microdefects and multiresolution numerical analysis, International Journal of Damage Mechanics, 23, 4, 537-566

12. Socha G., 2003, Experimental investigations of fatigue cracks nucleation, growth and coalescence in structural steel, International Journal of Fatigue, 25, 2, 139-147

13. Socha G., 2004, Prediction of the fatigue life on the basis of damage progress rate curves, International Journal of Fatigue, 26, 4, 339-347

14. Socha G., Dietrich L., 2012, Accumulation of damage in A336 GR5 structural steel subject to complex stress loading, Strain, 48, 279-285

15. Socha G., Dietrich L., 2014, A fatigue damage indicator parameter for P91chromiummolybdenum alloy steel and fatigue pre-damaged P54T carbon steel, Fatigue and Fracture of Engineering Materials and Structures, 37, 195-205

16. Socha G., Dietrich L., 2016, Deformation based fatigue damage accumulation model, Solid State Phenomena, 240, 128-133

17. Socha G., Madejski B., Krysztofik J., Czarnewicz S., 2014, Test method of structural damages caused by permanent deformation of the alloy in the test sample by tensile test and the sample to test damage of the alloy structure, Patent pending no. P-409294, Urząd Patentowy RP

18. YAnG B., Feng M.F., Zhai Z.Y., 2010, Evolutionary statistical character of fatigue damage of smooth surface samples by an effective short fatigue crack criterion, International Journal of Damage Mechanics, 19, 211-231

19. Yang L., Fatemi A., 1998, Cumulative fatigue damage mechanisms and quantifying parameters: a literature review, Journal of Testing and Evaluation, JTEVA, 26, 2, 89-100

20. ZhANG M., YANG P., TAN Y., 1999, Micromechanisms of fatigue crack nucleation and short crack growth in a low carbon steel under low cycle impact fatigue loading, International Journal of Fatigue, 21, 823-830 